\title{
MY CHILD HAS ADHD...AM I OK?": THE PSYCHOLOGICAL BURDEN OF CARING FOR AN ADHD CHILD IN LEBANON AND ITS ASSOCIATION TO Caregivers' Mental Health.
}

\author{
Melissa Matar and Nada Zahreddine \\ Lebanese University, Rafic Hariri Campus, Faculty of Public Health, Neuroscience \\ Research center, Department of Neuropsychology, Beirut, Lebanon \\ *Corresponding author: Melissa Matar \\ melissadouniamatar@gmail.com
}

(Received January 2019 - Accepted June 2019)

\begin{abstract}
Matar, M. and Zahreddine, N. 2019. "My child has ADHD...am I ok?": The Psychological Burden of caring for an ADHD child in Lebanon and its Association to Caregivers' Mental Health. Lebanese Science Journal, 20(3): 468-494.

Objectives: Previous studies have indicated that caregivers of ADHD children consider this disorder to be a psychological burden on their lives in all its aspects: social, occupational, and financial. As a result, these caregivers are marked with psychological morbidities including stress, anxiety and depression. While there have been reports of ADHD in Lebanon, there are no studies in Lebanon or in the Middle East that measure the psychological burden of ADHD on caregivers or its association to mental health. Therefore, this study aims to inspect the psychological burden of ADHD and assess the variation in stress, depression, and anxiety among caregivers of ADHD children. Methods: The study involves 120 Lebanese caregivers, 48 of which are caregivers of ADHD children and 72 are those of normally developing children. Caregivers are presented with three scales to report: DASS-21, SDQ and a CAPPA-adapted survey. Results: After analyzing the responses, we can infer that caregivers of ADHD children worry, avoid outside activities with their child, consider their child to be a strain on their family, on their occupation, and on their finances more than caregivers of normally developing children with $O R s=15.8,20.3,3.5,13$, and 3.7 respectively. Moreover, more caregivers of ADHD children reported depression (58\% vs 26\%) and anxiety (31\% vs $14 \%$ ) with higher mean scores on DASS-21 (mean=14.98+/-6.2, $p<0.001$ ) for depression and (mean $=15.67+/-5.02, p<0.001)$ for anxiety compared with caregivers of normally developing children. ORs $=4.7$ and 3.7 for depression and anxiety respectively. In addition, mental health seems to be positively associated with each of the psychological
\end{abstract}

http://dx.doi.org/10.22453/LSJ-020.3.468-494 National Council for Scientific Research - Lebanon 2018®) lsj.cnrs.edu.lb/vol-20-no-3-2019/ 
burden and severity of the child's ADHD. And in turn, the caregivers' psychological burden is also positively associated to the child's ADHD severity. Finally, mental health seems to be discriminant in caregiver gender, where more mothers show depression (64\%), anxiety (75\%) and stress (68\%) than fathers of ADHD children. Conclusion: This study affirms that caring for a child with ADHD impacts the mental health of caregivers and their lives. Therefore, there are strong grounds to contemplate ways to help such a vulnerable group of caregivers in the Lebanese population.

Keywords: caregivers, ADHD, burden, depression, anxiety.

\section{INTRODUCTION}

ADHD or attention deficit and hyperactivity disorder is a neurodevelopmental disorder known to affect children and adolescents worldwide (Wrońska et al., 2015). By DSM-5 standards, ADHD is characterized by patterns of inattention and/or hyperactivityimpulsivity which interferes with child functioning. ADHD can be categorized into three subtypes: the predominantly inattention subtype, hyperactive-impulsive subtype or combined subtype (Reynolds, 2013). According to the literature, and since ADHD is a chronic condition that persists regardless of psychotherapy, this disorder seems to have a substantial psychological burden on caregivers and affects their lives socially, occupationally and financially (Cussen et al., 2012; Flood et al., 2016; and Riley et al., 2006).

In that regard, when the European CAPPA study, assessed the different forms of the psychological burden of ADHD on caregivers in 2016, it was inferred that a reasonable percentage of caregivers reported having to quit or change their job despite their child being on medication. The study also noted that caregivers reported levels of strain in their social activities and family relationships and avoided social activities with their ADHD child. Moreover, further studies concluded that higher ADHD severity, male children, ADHD inattention symptoms, and the presence of comorbid ODD was associated with increased caregiver burden (Bussing et al., 2003; and Fridman, 2017). In addition, this disorder also presents with a financial burden, as deduced by the 2011 Medical Expenditure Panel Survey database, stating that ADHD cohorts had higher expenditures than non-ADHD cohorts (Gupte-Singh et al., 2017). Finally, ADHD seems to hold major gravity with regard to quality of life, even when compared with other conditions. In fact, it was found that out of five conditions (asthma, eczema, dyslexia, ADHD, and migraine), the families of children with migraines and in particular children with ADHD exhibited lower QOL scores (Bai et al., 2017).

All of this makes this disorder particularly difficult for caregivers and creates an immense psychological burden on them thus substantially impacting their mental health. This was suggested by Cadman who inferred that the psychological burden of ADHD and/or autism in adolescents is related to parental depression and anxiety (Cadman et al., 2012). In fact, mothers of ADHD children tend to have a high level of depression due to the self-perception of being stigmatized by other mothers (Norvilitis et al., 2002). This might apply even more in Middle Eastern countries such as Lebanon, where the stigma towards mental illness is indeed inflated (Farah et al., 2009). 
Furthermore, a study found that C-ADHDC (Caregivers of ADHD children) had higher depression, anxiety and stress based on the DASS-21 scores than C-NDC (Caregivers of normally developing children) (Cussen et al., 2012). Such burden was explained physiologically, linking the stress of caregiving for an ADHD child with the dysregulation of the (HPA) axis (Lovell et al., 2012). In fact, caring for a child with a disability indicated a flattening of the diurnal cortisol slope, and hypo secretion of cortisol (Bella et al., 2011; Lovell et al., 2015; and Seltzer et al., 2010). Finally, when it comes to local studies, no studies were found in Lebanon or the Middle East assessing the mental health in C-ADHDC or the psychological burden of caring for an ADHD child. However, a Lebanese study has found that based on a sample of 127 Lebanese mothers of children with several intellectual disabilities, a substantial percentage of mothers were found to be depressed (Azar et al., 2006).

Therefore, the objective of this study lies in two domains: first, to determine the psychological burden that ADHD has on caregivers of ADHD children in a representative sample of Lebanese adults as well as assess the population's demographics. Second, to study ADHD's clinical impact on caregivers.

\section{METHODOLOGY}

\section{Study design}

The present study is a case-control study conducted from September 2017 till June 2018. The study is made of a representative Lebanese sample of 120 adults. The case group includes $48 \mathrm{C}$-ADHDC while the control group includes $72 \mathrm{C}$-NDC from different regions in Lebanon.

\section{Ethical considerations}

The study was approved by the neuroscience research center in the Lebanese University- Hadath. Moreover, a parent form was given to parents participating in this study. It explains about the nature of the study, its utilized psychological measures, its anonymity, its respect for privacy, and its optional participation. Parents were only included in the study if their written consent was given accordingly.

\section{Participants}

Specialists and Lebanese private inclusive schools whose contact information was received from the public ministry of health were contacted. After explaining to the clinicians and schools the protocol of the study, 10 specialists and one private school: Central College Jounieh (CCJ) agreed to participate in the study. Caregivers of the clinicians' patients and the school's students were thus contacted and included in the study after their written consent was given. Note that, caregivers were excluded from the study if they had been diagnosed with depression/anxiety before their child was born as this creates an issue of misinterpreted causality. 


\section{Procedure and assessment measures}

In order to confirm the diagnosis of ADHD and conduct disorder in children, the SDQ, a psychological scale that tests for inattention, hyperactivity and behavioral symptoms, was administered to caregivers. Standardized evaluation was also performed by the school psychologist and the clinicians involved in the study. Based on the parents' preference and after reading the parent form, parents' response was either collected via a hardcopy or an online anonymous survey. Parents of students of CCJ who were CADHDC were uniformly selected after their child's diagnosis was confirmed, and C-ND students were randomly selected according to the student number from grade one to grade 11. After accounting for a (67\%) response rate, and for one caregiver previously diagnosed with depression who was excluded from the study, data was collected from a sample of 48 cases and 72 controls making the total number of the sample 120 caregivers.

Three scales were used in this study: the DASS-21 scale for assessing the caregivers' mental health, the psychological burden survey adjusted from the CAPPA survey for assessing the psychological burden of ADHD, and the SDQ for assessing the child's ADHD. All measures used in this study were self-administered by the caregivers, validated and presented to the sample in English and Arabic.

\section{SDQ}

The ascertainment of the child's diagnosis with ADHD was made according to the SDQ or Strength and Difficulties Questionnaire. The SDQ is one of the most internationally used behavioral scales. The scale is applied to children suffering from various disorders, including ADHD. The twenty-five-item SDQ contains five subscales accounting for: emotional symptoms, conduct problems, hyperactivity-attention, peer relationship problems, and prosocial behavior. For this study however, since we are only interested in screening for ADHD, only scores for the hyperactivity-attention (HA) and conduct disorder (CD) subscales were taken forward for analyses with hyperactivity and inattention being the main symptoms of ADHD and CD being the most common comorbidity to ADHD (Turgay et al., 2005). As proven, these two subscales despite their brevity performed similarly in identifying ADHD as the full SDQ (Algorta, 2016). In brief, caregivers were asked to rate whether their child's behaviors are, 0 (not true), 1 (somewhat true), or 2 (certainly true), with higher scores indicating more problematic behaviors. Scores ranging from 4-10 on the conduct subscale, as well as scores ranging from 7-10 on the hyperactivity subscale were deemed abnormal (Goodman et al., 2004). Lastly, the SDQ had high specificity (80\%) and sensitivity (85\%) (Goodman, 1997), and was tested for internal consistency and reliability in the present study using Cronbach's alpha. As a result, SDQ had an adequate alpha $=0.71$ and 0.79 for CD and HA, similar to the literature (Alyahri and Goodman, 2006).

\section{Psychological burden survey}

Modules indicating the psychological burden of ADHD and sociodemographic variables were collected via a survey adjusted and adapted from the European CAPPA 
survey according to the aims and the population of this study. The survey is of 21 questions and is divided into three sections: The first section accounts for demographic variables such as age, gender, level of education, financial status, and number of children... The second section accounts for the child's ADHD and his/her primary caregiver. This section addresses the child being on or off medication, the type of medication being used, and the presence of another sibling with a mental health problem...Finally, the last section accounts for the modules of psychological burden such as the amount of burden the child puts on the caregivers and his/her family, whether the caregiver avoids outside activities with the child, and the amount of burden the child puts on the caregiver's finances...All of which are items answered on a 5 point Likert scale, with higher points indicating a higher level of burden. The psychological burden survey had a Cronbach alpha of 0.9 .

\section{DASS-21}

The DASS-21 or Depression Anxiety and Stress Scale is a psychological parameter used to assess three types of emotional dimensions. One sub-scale of DASS assesses the presence of depression with items on dysphoria, dissatisfaction, anhedonia, and inertia. The items from the anxiety scale measure autonomic arousal, muscular effects, and anxiety. The items on the stress scale include agitation and irritability. Items are measured on a four-point Likert scale ranging from zero ("Did not apply to me at all") to three ("Applied to me very much"). The scale is divided into normal, mild, moderate, severe and extremely severe in each of the three categories: stress, depression and anxiety. As for validity, the English version of the DASS-21 showed a very good internal consistency with Cronbach's $\alpha$ of $(0.88,95 \%$ CI $1 / 4.87-.89)$ for the depression scale, $(0.82,95 \%$ CI $1 / 40.80-0.83)$ for the anxiety scale, and $(0.90,95 \%$ CI $1 / 40.89-0.91)$ for the stress scale. DASS-21 showed an $\alpha$ of $(0.93,95 \%$ CI $1 / 40.93-0.94)$ for the total scale (Henry et al., 2005). Furthermore, the Cronbach's alpha reliability coefficient indicated excellent internal consistency for the Arabic DASS-21: Cronbach's alphas for stress, anxiety, depression, and total DASS- 21 being 0.70, 0.68 and 0.65 respectively (Taouk et al., 2001).

\section{Statistical analyses and data interpretation}

First, Schapiro Wilk's test was performed to assess a normal distribution of data. In that regard, DASS and SDQ scales had a normal distribution with $\mathrm{p}>0.05$ and were treated by parametric tests such as student $t$ test and Pearson correlation. Whereas, individual items and the total scale of the psychological burden survey were not normally distributed and were considered as ordinal variables (Brown, 2011). In this case, nonparametric tests were used such as Man Whitney U test and ordinal regression. For the psychological burden scale, variables were reverse coded so that higher ratings indicate a higher burden. Moreover, Chi-square analyses were used to evaluate the significance of differences among proportions of categorical data. Concerning the caregivers' mental health, the odds ratios and (95\%) confidence intervals obtained from logistic regression were taken as measures of association with dependent variables being 
dichotomized (Al-Farsi et al., 2016). As for regression models, two separate linear models were used. ADHD and conduct symptoms often occur together; this makes it difficult to adjust for conduct symptoms without possibly removing the effect of the child's ADHD. Thus, the first regression models adjust for socio-demographic factors only and the second adjust for the latter in addition to conduct symptoms. Confounders were spotted when OR change >10 \% (Becher, 1992) and (Lee and Burstyn, 2016).

\section{RESULTS}

\section{Sociodemographic data}

Male children in the case group were more numerous than female ones (75\% vs $50 \%$ ). Also caregivers in the case group were less educated than those in the control group with illiteracy and university graduates being (10.3\% vs $2.7 \%)$ and $(37.5 \%$ vs $44.5 \%)$ respectively. Moreover, (66.7\%) of ADHD children were on medication, the two most common medications being Strattera and Ritalin. Finally, $(35.4 \%)$ of C-ADHDC reported having a child with a mental health problem other than ADHD compared to (4.2 $\%$ ) of C-NDC and only (12.5\%) of C-ADHDC reported seeking psychotherapy compared to $(8.3 \%)$ in the control group (Table 1$)$.

Table 1. The sociodemographic data of caregivers in the case and control group.

\begin{tabular}{|l|l|l|l|l|}
\hline \multirow{2}{*}{ Sociodemographic Variables } & \multicolumn{2}{l|}{ Sample } & \multicolumn{2}{l|}{} \\
\cline { 3 - 5 } & Case Group* & Control Group* & P value* \\
\hline \multirow{4}{*}{ Kinship } & Mother & $56.20 \%$ & $60.30 \%$ & 0.27 \\
& Father & $37.50 \%$ & $36.30 \%$ & \\
& Other & $6.30 \%$ & $3.40 \%$ & \\
\hline \multirow{2}{*}{ Child gender } & Male & $75.00 \%$ & $50.00 \%$ & \\
& Female & $25.00 \%$ & $50.00 \%$ & \\
\hline \multirow{3}{*}{ Child age } & Age 6-12 & $56.50 \%$ & $66.70 \%$ & 0.92 \\
\hline \multirow{3}{*}{ Caregiver age } & Age 13-17 & $43.50 \%$ & $33.30 \%$ & \\
& Age $<30$ & $8.30 \%$ & $5.60 \%$ & 0.05 \\
\hline
\end{tabular}




\begin{tabular}{|c|c|c|c|c|}
\hline Number of children & $\begin{array}{l}1-2 \text { children } \\
3-4 \text { children } \\
>4 \text { children }\end{array}$ & $\begin{array}{l}47.90 \% \\
50.00 \% \\
2.10 \%\end{array}$ & $\begin{array}{l}51.40 \% \\
45.80 \% \\
2.80 \%\end{array}$ & 0.48 \\
\hline Marital status & $\begin{array}{l}\text { Married } \\
\text { Divorced } \\
\text { Widower }\end{array}$ & $\begin{array}{l}68.80 \% \\
20.80 \% \\
10.40 \%\end{array}$ & $\begin{array}{l}86.10 \% \\
11.10 \% \\
2.80 \%\end{array}$ & 0.05 \\
\hline Level of education & $\begin{array}{l}\text { University } \\
\text { High school } \\
\text { Grade } 9 \\
\text { Illiterate }\end{array}$ & $\begin{array}{l}35.70 \% \\
35.40 \% \\
18.60 \% \\
10.30 \%\end{array}$ & $\begin{array}{l}44.50 \% \\
47.20 \% \\
5.60 \% \\
2.70 \%\end{array}$ & 0.02 \\
\hline Occupational status & $\begin{array}{l}\text { Fulltime } \\
\text { Part time } \\
\text { Unemployed }\end{array}$ & $\begin{array}{l}52.10 \% \\
31.20 \% \\
16.70 \%\end{array}$ & $\begin{array}{l}51.40 \% \\
25.00 \% \\
23.60 \%\end{array}$ & 0.58 \\
\hline Economic status & $\begin{array}{l}\text { Low class } \\
\text { Middle class } \\
\text { High class }\end{array}$ & $\begin{array}{l}20.80 \% \\
54.20 \% \\
25.00 \%\end{array}$ & $\begin{array}{l}20.80 \% \\
62.50 \% \\
16.70 \%\end{array}$ & 0.51 \\
\hline $\begin{array}{l}\text { Another child with a } \\
\text { mental health problem }\end{array}$ & $\begin{array}{l}\text { Yes } \\
\text { No }\end{array}$ & $\begin{array}{l}35.40 \% \\
64.60 \%\end{array}$ & $\begin{array}{l}4.20 \% \\
95.80 \%\end{array}$ & $<0.001$ \\
\hline Taking medication & $\begin{array}{l}\text { Yes } \\
\text { No }\end{array}$ & $\begin{array}{l}66.70 \% \\
33.30 \%\end{array}$ & $\begin{array}{l}0.00 \% \\
0.00 \%\end{array}$ & \\
\hline Medication & $\begin{array}{l}\text { Strattera } \\
\text { Concerta } \\
\text { Ritalin } \\
\text { Risperidone }\end{array}$ & $\begin{array}{l}37.50 \% \\
25.00 \% \\
31.20 \% \\
6.20 \%\end{array}$ & $\begin{array}{l}0.00 \% \\
0.00 \% \\
0.00 \% \\
0.00 \%\end{array}$ & \\
\hline Psychological therapy & $\begin{array}{l}\text { Yes } \\
\text { No }\end{array}$ & $\begin{array}{l}12.50 \% \\
87.50 \%\end{array}$ & $\begin{array}{l}8.30 \% \\
91.70 \%\end{array}$ & 0.45 \\
\hline
\end{tabular}

Case group: Caregivers of ADHD children/Control group: Caregivers of non-ADHD children/ $\mathrm{P}$ values obtained by Student's t test for numerical variables and Chi2 test for nominal variables.

\section{Bivariate analysis}

\section{Caregiver burden}

Table 2 shows responses from the CAPPA adjusted survey.

Table 2. Frequency table of the psychological burden items in the case and control group

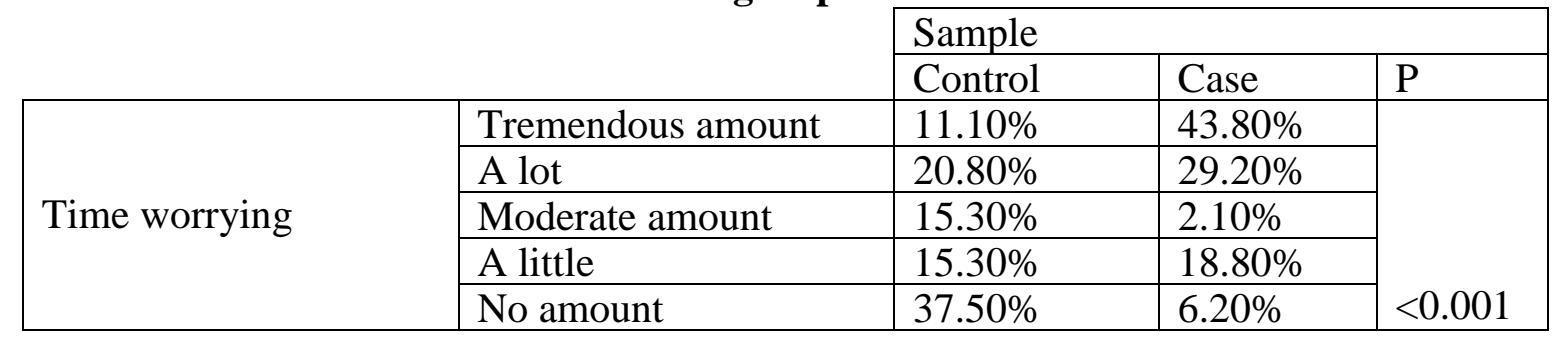




\begin{tabular}{|c|c|c|c|c|}
\hline \multirow{5}{*}{ Strain on family } & Tremendous amount & $0.00 \%$ & $4.20 \%$ & \multirow[b]{5}{*}{$<0.001$} \\
\hline & A lot & $2.80 \%$ & $16.70 \%$ & \\
\hline & Moderate amount & $11.10 \%$ & $18.80 \%$ & \\
\hline & A little & $2.80 \%$ & $12.50 \%$ & \\
\hline & No amount & $83.30 \%$ & $47.90 \%$ & \\
\hline \multirow{5}{*}{ Avoid outside activity } & Almost all the time & $0.00 \%$ & $14.60 \%$ & \multirow[b]{5}{*}{$<0.001$} \\
\hline & Most of the time $(75 \%)$ & $0.00 \%$ & $10.40 \%$ & \\
\hline & Some of the time $(50 \%)$ & $9.70 \%$ & $25.00 \%$ & \\
\hline & A little of the time & $4.20 \%$ & $15.80 \%$ & \\
\hline & Never $(0 \%)$ & $86.10 \%$ & $34.20 \%$ & \\
\hline \multirow{5}{*}{$\begin{array}{l}\text { Worry about others' } \\
\text { perceptions }\end{array}$} & Almost all the time & $5.00 \%$ & $6.20 \%$ & \multirow[b]{5}{*}{0.9} \\
\hline & Most of the time $(75 \%)$ & $15.00 \%$ & $18.80 \%$ & \\
\hline & Some of the time $(50 \%)$ & $16.10 \%$ & $18.80 \%$ & \\
\hline & A little of the time & $13.80 \%$ & $18.80 \%$ & \\
\hline & Never $(0 \%)$ & $50.10 \%$ & $37.50 \%$ & \\
\hline \multirow{5}{*}{ Strain on job } & Tremendous amount & $0.00 \%$ & $4.20 \%$ & \multirow[b]{5}{*}{$<0.001$} \\
\hline & A lot & $0.00 \%$ & $6.20 \%$ & \\
\hline & Moderate amount & $0.00 \%$ & $16.70 \%$ & \\
\hline & A little & $5.60 \%$ & $29.20 \%$ & \\
\hline & No amount & $94.40 \%$ & $43.80 \%$ & \\
\hline \multirow{5}{*}{ Financial burden } & Tremendous amount & $0.00 \%$ & $14.60 \%$ & \multirow[b]{5}{*}{$<0.001$} \\
\hline & A lot & $2.80 \%$ & $18.80 \%$ & \\
\hline & Moderate amount & $1.40 \%$ & $8.30 \%$ & \\
\hline & A little & $22.20 \%$ & $12.50 \%$ & \\
\hline & No amount & $73.60 \%$ & $45.80 \%$ & \\
\hline
\end{tabular}

$\mathrm{P}$ value obtained from the Man Whitney $\mathrm{U}$ test.

As shown, C-ADHDC reported more time worrying (94\% vs $62.5 \%$ ) and a larger amount of social strain $(52 \%$ vs $17 \%) \quad(p<0.001)$ with respect to C-NDC. C-ADHDC also avoided taking their child outside (66\% vs $14 \%$ ), and reported their child as an occupational burden more than controls: $(56 \%$ vs $6 \%)$ with $(\mathrm{p}<0.001)$. Finally, CADHDC reported their child to be a financial burden more than controls (54\% vs 26\%). This was concordant with a study that found that raising an ADHD child 5 times more than raising a child without ADHD (Zhao et al., 2019). In general, we can infer that CADHDC considered their child a psychological burden on their lives more than C-NDC, in all aspects except one which is: "worrying about other people's perceptions". This item was insignificantly different ( $\mathrm{p}=0.91$ ) with responses being equally inflated in the control and case group. This might suggest different psychosocial behaviors when it comes to Middle Eastern societies where an increased amount of worrying in Lebanese caregivers about what others think of them as parents might originate from a less liberated society which puts pressure on parents to be traditional and follow stringent rules when raising their child regardless of whether or not the child has a mental health problem (Amer, 2014; and Wrobel, 2013).

Furthermore, in order to check if pharmacotherapy influenced caregiver burden, C- ADHDC were stratified based on whether the child is on/off medication as shown in table 3 . As a result, (44\% vs $19.5 \%$ ) of C-ADHDC who were on medication did not avoid 
taking their child to outside activities, (46.8\% vs $23.7 \%$ ) did not consider their child as a financial burden, and (37.5\% vs $14.5 \%)$ did not consider their child as a family strain. However, (53.2-62.5\%) of the case group still reported some levels of strain in these domains even if their child was on medication suggesting that there may be unmet needs in the complete management of ADHD by pharmacological interventions (Preuss et al., 2006; and Ralston et al., 2004).

Table 3. The psychological burden in C-ADHDC who are on vs off medication.

\begin{tabular}{|c|c|c|c|c|}
\hline \multicolumn{2}{|l|}{ Psychological burden } & \multicolumn{3}{|c|}{$\begin{array}{l}\text { Caregivers of ADHD children } \\
\text { Taking medication }\end{array}$} \\
\hline & & Yes & No & P value* \\
\hline \multirow{5}{*}{ Time worrying } & Tremendous amount & \multirow{5}{*}{$\begin{array}{l}5.90 \% \\
3.10 \% \\
25.00 \% \\
21.90 \% \\
44.10 \%\end{array}$} & \multirow{5}{*}{$\begin{array}{l}10.50 \% \\
7.50 \% \\
36.20 \% \\
12.50 \% \\
33.30 \%\end{array}$} & \multirow{5}{*}{0.81} \\
\hline & A lot & & & \\
\hline & Moderate amount & & & \\
\hline & A little & & & \\
\hline & No amount & & & \\
\hline \multirow{5}{*}{ Strain on family } & Tremendous amount & $3.20 \%$ & $8.20 \%$ & \multirow{5}{*}{0.03} \\
\hline & A lot & $18.80 \%$ & $20.50 \%$ & \\
\hline & Moderate amount & $20.00 \%$ & $31.20 \%$ & \\
\hline & A little & $20.50 \%$ & $25.60 \%$ & \\
\hline & No amount & $37.50 \%$ & $14.50 \%$ & \\
\hline \multirow{5}{*}{ Avoid outside activity } & Almost all the time $(90 \%)$ & $12.60 \%$ & $16.50 \%$ & \multirow{5}{*}{0.02} \\
\hline & Most of the time $(75 \%)$ & $6.50 \%$ & $10.20 \%$ & \\
\hline & Some of the time $(50 \%)$ & $18.10 \%$ & $28.80 \%$ & \\
\hline & A little of the time $(25 \%)$ & $18.80 \%$ & $25.00 \%$ & \\
\hline & Never $(0 \%)$ & $44.00 \%$ & $19.50 \%$ & \\
\hline \multirow{4}{*}{$\begin{array}{l}\text { Worry about others' } \\
\text { perceptions }\end{array}$} & Almost all the time $(90 \%)$ & $6.20 \%$ & $6.20 \%$ & \multirow{4}{*}{0.91} \\
\hline & Most of the time $(75 \%)$ & $18.80 \%$ & $18.80 \%$ & \\
\hline & Some of the time $(50 \%)$ & $12.90 \%$ & $21.50 \%$ & \\
\hline & A little of the time $(25 \%)$ & $12.50 \%$ & $31.20 \%$ & \\
\hline
\end{tabular}




\begin{tabular}{|c|c|c|c|c|}
\hline & Never $(0 \%)$ & $40.60 \%$ & $31.30 \%$ & \\
\hline \multirow{5}{*}{ Strain on job } & Tremendous amount & $3.10 \%$ & $6.20 \%$ & \multirow{5}{*}{0.14} \\
\hline & A lot & $6.20 \%$ & $6.20 \%$ & \\
\hline & Moderate amount & $15.60 \%$ & $18.80 \%$ & \\
\hline & A little & $31.90 \%$ & $33.80 \%$ & \\
\hline & No amount & $43.10 \%$ & $35.00 \%$ & \\
\hline \multirow{5}{*}{ Financial burden } & Tremendous amount & $2.50 \%$ & $8.80 \%$ & \multirow{5}{*}{0.01} \\
\hline & A lot & $11.90 \%$ & $22.50 \%$ & \\
\hline & Moderate amount & $19.40 \%$ & $26.20 \%$ & \\
\hline & A little & $19.40 \%$ & $18.80 \%$ & \\
\hline & No amount & $46.80 \%$ & $23.70 \%$ & \\
\hline
\end{tabular}

$\mathrm{P}$ value obtained from the Man Whitney $\mathrm{U}$ test.

Finally, it was suspected that ADHD severity is correlated to caregiver burden thus the correlation between the child's ADHD severity and the psychological burden of ADHD was tested by the Spearman test. As a result, the correlation is significant and positive with a moderate strength (Mukaka, 2012). This is shown in table 4. By examining figure 1, we can also see that as the child's SDQ-HA scores are increasing from 3 to 10, the psychological burden is also increasing reaching 5, and a positive trend is noted. Thus, we can infer that, the more severe the child's ADHD, the higher the psychological burden placed on his/her caregivers (Theule, 2013). In fact, ADHD severity, particularly in the hyperactivity subtype, joined with symptoms associated to aggression, emotional lability, and executive functioning difficulties is known to elevate parental burden levels (MuñozSilva et al., 2017; and Graziano, 2011). The more severe the child's ADHD the more likely the caregiver is to reduce social and labor activities (Latha et al., 2012).

Table 4. The correlation between the child's ADHD severity and the psychological burden of ADHD in C-ADHDC.

\begin{tabular}{|l|l|}
\cline { 2 - 2 } \multicolumn{1}{c|}{} & SDQ-HA and Psychological burden \\
\hline Correlation coefficient & 0.72 \\
\hline P value* $^{*}$ & $<0.001$ \\
\hline
\end{tabular}

$P$ value obtained by Spearman correlation test. 


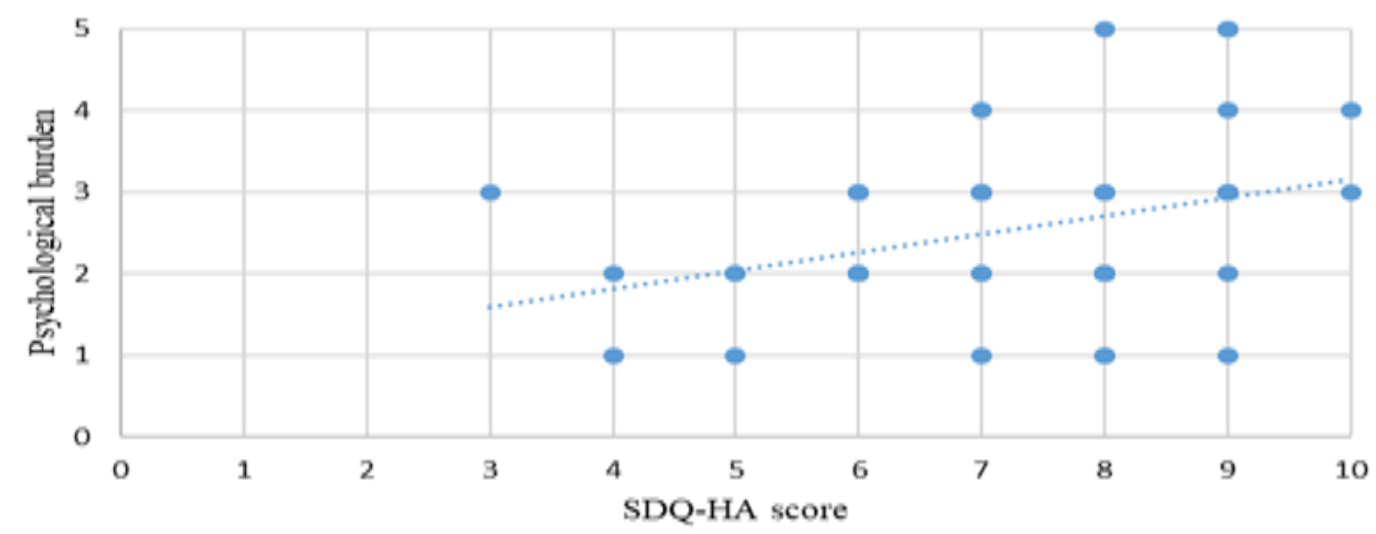

Figure 1. The association between the child's ADHD severity and the psychological burden of ADHD.

\section{Caregiver clinical impact}

In order to assess the clinical impact of ADHD on caregivers, student's t test was performed on DASS-21 variables. Table 5 shows that significantly higher mean scores were endorsed in the case group vs the control group: $(14.98+/-6.2)$ vs $(4.31+/-4.24)$ for depression and (15.67+/- 5.02) vs (4.97+/- 4.00) for anxiety. Stress on the other hand was not statistically significant. This might be due to several factors specific to the Lebanese population that might have alleviated stress at baseline compared with Euro-American populations rendering the difference between the two groups insignificant. These factors might include; domestic violence combat, war and traumatic events, and terrorism and political instability (Fares et al., 2017; Khadra et al., 2015; and Shamai and Kimhi, 2006). Results were also affirmed in table 6 , where C-ADHDC endorsed higher percentages on depression (58\%) and anxiety (31\%) compared to (26\%) and (14\%) in C-NDC.

Table 5. The mean scores of DASS-21 in the case and control group.

\begin{tabular}{|l|l|l|l|l|l|l|l|}
\cline { 2 - 8 } \multicolumn{1}{c|}{} & \multicolumn{2}{l|}{ Case group } & \multicolumn{2}{l|}{ Control group } & \multirow{2}{*}{ MD } & \multirow{2}{*}{ CI } & \multirow{2}{*}{ P value } \\
\cline { 2 - 8 } \multicolumn{1}{c|}{} & Mean & SD & Mean & SD & & & \\
\hline Depression Score & 14.98 & 6.2 & 4.31 & 4.24 & 10.67 & $8.77-12.57$ & $<0.001$ \\
\hline Anxiety Score & 15.67 & 5.02 & 4.97 & 4 & 10.69 & $9.05-12.33$ & $<0.001$ \\
\hline Stress Score & 14.58 & 3.35 & 11.28 & 10.52 & 3.3 & $3.03-6.58$ & 0.09 \\
\hline
\end{tabular}

Table 6. Frequency table of DASS-21 in the case and control group.

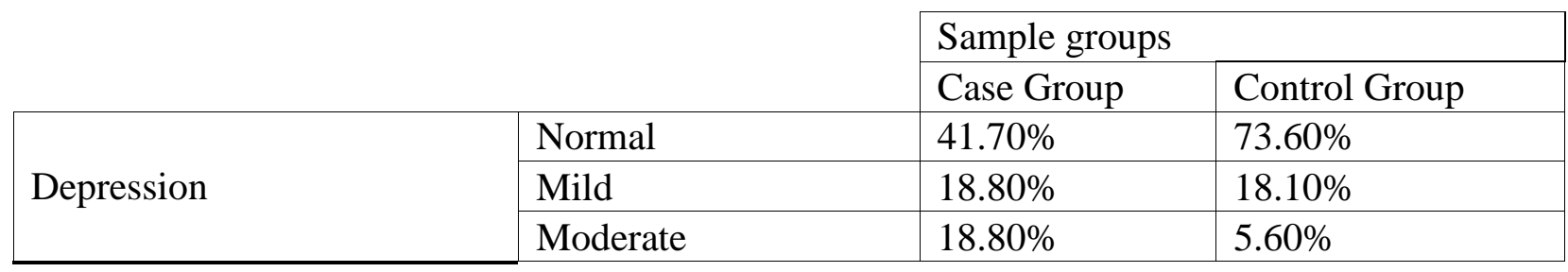




\begin{tabular}{|l|l|l|l|}
\cline { 2 - 4 } & Severe & $14.60 \%$ & $2.80 \%$ \\
\cline { 2 - 4 } Anxiety & Extremely severe & $6.20 \%$ & $0.00 \%$ \\
\hline \multirow{5}{*}{ Stress } & Normal & $68.80 \%$ & $86.10 \%$ \\
\cline { 2 - 4 } & Mild & $18.80 \%$ & $12.50 \%$ \\
\cline { 2 - 4 } & Moderate & $8.30 \%$ & $1.40 \%$ \\
\cline { 2 - 4 } & Severe & $0.00 \%$ & $0.00 \%$ \\
\cline { 2 - 4 } & Extremely severe & $4.20 \%$ & $0.00 \%$ \\
\hline & Normal & $45.10 \%$ & $57.40 \%$ \\
\cline { 2 - 4 } & Mild & $25.00 \%$ & $16.90 \%$ \\
\cline { 2 - 4 } & Moderate & $12.50 \%$ & $10.40 \%$ \\
\cline { 2 - 4 } & Severe & $15.30 \%$ & $12.50 \%$ \\
\cline { 2 - 4 } & Extremely severe & $2.10 \%$ & $2.80 \%$ \\
\hline
\end{tabular}

Furthermore, the correlation between the child's ADHD severity and the caregivers' DASS indices, was tested (Table 7). As a result, the correlation between a child's ADHD severity and each of depression and anxiety is significant and positive with high strength with $\mathrm{p}<0.001$ (Richa et al., 2014). Stress however, is not significantly related to a child's SDQ-HA scores. The scatter plots for each of anxiety and depression with respect to the child's ADHD severity were also examined, one can spot a positive association. In brief, as the child's SDQ-HA scores are increasing from 3 to 10, the caregivers' anxiety and depression scores are also increasing reaching a score of approximately 20, (Figure 2). Thus, we can deduce that the more severe the child's ADHD, the more depressed and anxious the caregiver is (Brown, 2011). In fact, studies show that when a child displays severe hyperactivity and/or oppositional behavior (a symptom of conduct disorder; a common comorbidity to ADHD), even parents with a high level of care, may respond with dissatisfaction, anger and intolerance since their perceptions of the demands of their role as parents exceed their resources to cope with their child. As a result, caregivers would suffer from self-disparaging, apprehensiveness and worrying about their performance or loss of control of their child's behavior, all of which are early symptoms of depression and anxiety (Muñoz-Silva et al., 2017). Other studies suggest that a child's ADHD severity increases conduct problems which in turn serves as a mediating role and increases paternal depression (Donenberg and Baker, 1993).

Table 7. The correlation between a child's ADHD severity and DASS indices

\begin{tabular}{|l|l|l|l|}
\cline { 2 - 4 } \multicolumn{1}{c|}{} & Depression & Anxiety & Stress \\
\hline Correlation coefficient & 0.71 & 0.74 & 0.29 \\
\hline P value* & $<0.001$ & $<0.001$ & 0.42 \\
\hline
\end{tabular}

$P$ value obtained by Pearson correlation test. 

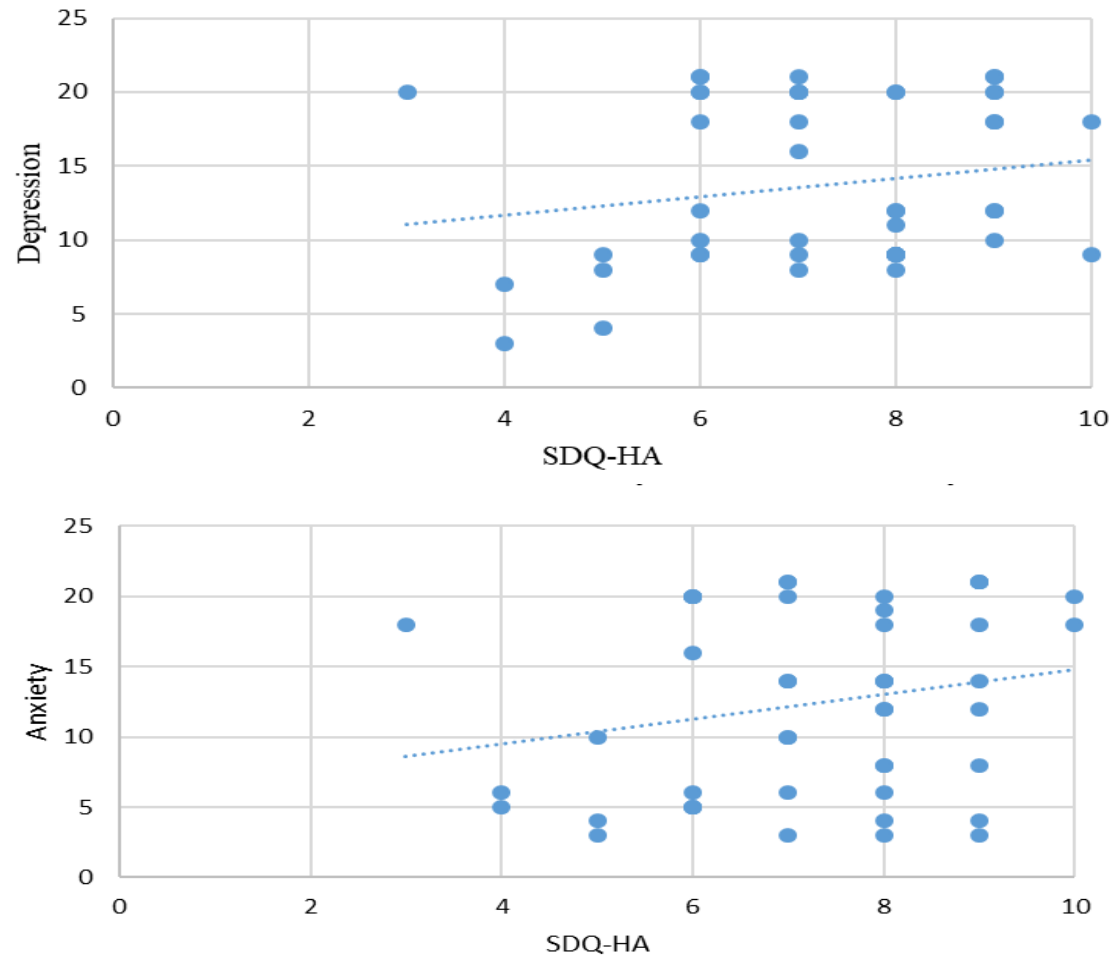

Figure 1. The association between the child's ADHD severity and the caregiver's depression and anxiety.

In addition, gender difference in DASS scores was also tested to see if mothers of ADHD children are more prone to mental health deterioration than fathers (McCubbin, 1983). Based on (Figure 3), (67\%), (68\%) and (63\%) of C-ADHDC who have depression, anxiety and stress respectively are mothers. 

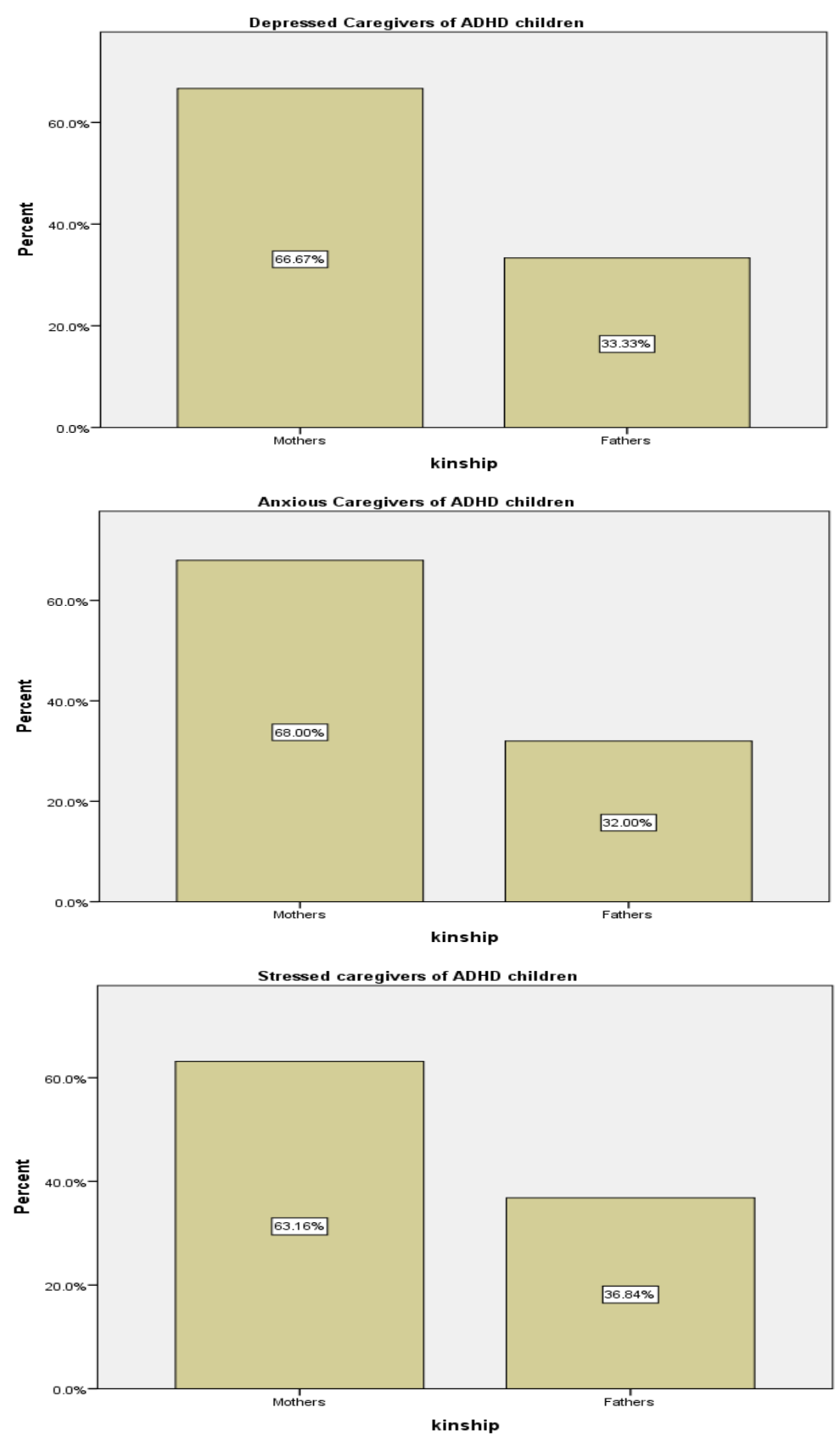

Figure 3. Gender distribution in depressed, anxious and stressed caregivers of ADHD children.

From table 8 , we can infer that this difference is statistically significant $(\mathrm{p}<0.05)$ and the relationship between caregiver gender and each of depression, anxiety and stress is a positive relationship with moderate strength (Yule, 1912) (Table 8). In fact, mothers are mostly affected by caregiving strain because they are the primary caregivers of the child (McCubbin and Patterson 1983), whereas fathers are often less engaged in this responsibility and this lack of paternal involvement is even greater in Middle Eastern countries (Zahr and Hattar 1998). 
Table 8. The significance of gender differences between DASS indices in the case group.

\begin{tabular}{|l|l|l|l|l|l|l|}
\cline { 2 - 7 } \multicolumn{2}{c|}{} & \multicolumn{2}{l|}{ Depression } & \multicolumn{2}{l|}{ Anxiety } & \multicolumn{2}{l|}{ Stress } \\
\hline Chi-Square Tests & Value & P value & Value & P value & Value & P value \\
\hline Pearson Chi-Square & 5.486 & 0.019 & 6.00 & 0.01 & 5.37 & 0.02 \\
\hline Phi coefficient & 0.33 & 0.01 & 0.35 & 0.01 & 0.33 & 0.02 \\
\hline
\end{tabular}

$\mathrm{P}$ value obtained by Chi2.

Moreover, in order to assess the gravity of the stigma related to seeking psychotherapy in Lebanon, caregivers who screened positive for DASS-21 were categorized based on whether they consulted with a psychotherapist regarding their mental health (Figure 4).
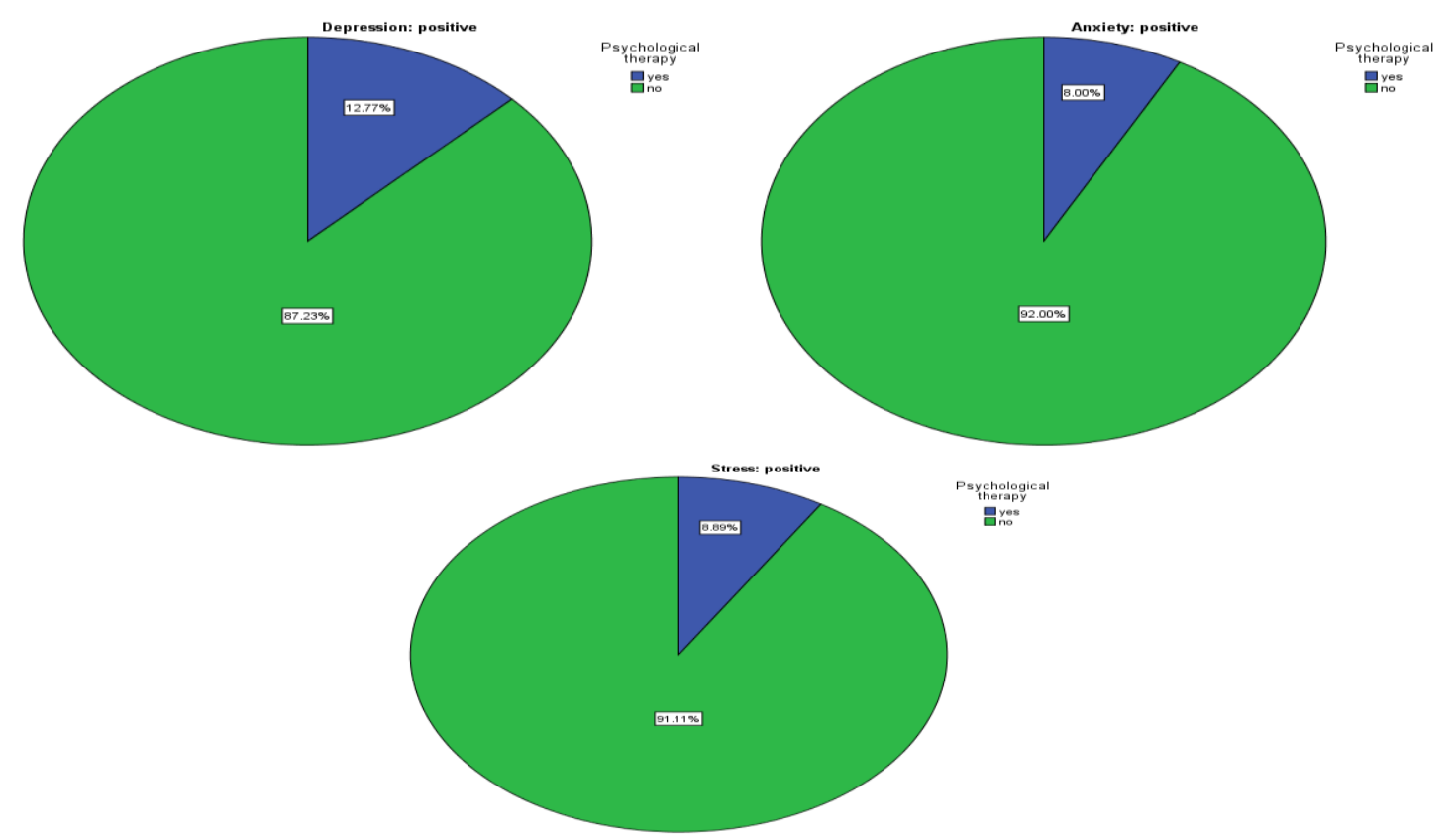

Figure 4. Psychotherapy in depressed, anxious and stressed caregivers.

As shown, only (12.7\%), (8\%) and (8.8\%) of depressed, anxious and stressed caregivers respectively, seek or have sought medical assistance regarding their mental health. Thus affirming the sad truth of how stigmatized mental health problems are in Lebanon, where individuals are reluctant to visit mental health care services because they are wary of being ostracized (Lauber and Rossler, 2007; and Lee, 2011). In fact, this diminished likelihood of seeking psychotherapy not only affects the caregivers, but will also indirectly affect the child's prognosis via parenting styles. In that regard, ADHD in a child can influence parent behavior, and vice versa, parent behavior can impact the presentation and development of both child conduct and ADHD symptoms (Johnston and Short, 1993). And while bad parenting caused by maternal depression does not directly cause ADHD, good parenting does seem to mitigate it (Pelham et. al, 1998). 
At last, in order to check if the two domains of the study (psychological burden of ADHD and its clinical impact on caregivers) are inter-related, the association between the psychological burden of ADHD and the caregivers' mental health was tested in the case group. Table 9 shows that the psychological burden of ADHD is positively and moderately associated to all mental health indices depression, anxiety and stress with $\mathrm{p}<0.001$. Therefore, we can state that the more the caregiver views his/her child as a psychological burden, the more he is depressed, anxious or stressed.

Table 9. The correlation between the psychological burden of ADHD and DASS indices.

\begin{tabular}{|l|l|l|l|}
\cline { 2 - 4 } \multicolumn{1}{c|}{} & Depression & Anxiety & Stress \\
\hline Correlation coefficient & 0.74 & 0.74 & 0.68 \\
\hline P value* & $<0.001$ & $<0.001$ & $<0.001$ \\
\hline
\end{tabular}

$P$ values obtained by Pearson correlation test.

\section{Multivariate analysis}

\section{ADHD predicts caregiver burden}

In order to delineate the relationship between the child's ADHD and its psychological burden on caregivers, ordinal regression was performed (Tables 10 and 11). After adjusting for the necessary covariates, all results that were significant at the 5\% crude level remained so. When sociodemographic data were entered in the model, all items except "family strain" and "financial burden" were confounded. In the second model, all the psychological burden items remained significant and were influenced by conduct problems and sociodemographic data (Zahr et al., 1998). Caregiver burden was analyzed according to seven variables. In general, C-ADHDC were roughly 3.5 and 13 times more likely to consider their child as a family and occupational strain respectively compared with controls. Also C-ADHDC were 3.7 times to consider their ADHD child as a financial burden than C-NDC. Finally, the two variables that showed the highest Odds Ratios are "avoiding outside activities with the child" and "time spent worrying" with ORs $=20.2$ and 15.8 respectively.

Table 10. Unadjusted analysis of the psychological burden items in caregivers of ADHD children.

\begin{tabular}{|l|l|l|l|l|}
\hline Dependent variables: & Odds Ratio (O.R) & \multirow{2}{*}{ P value } & \multicolumn{2}{|c|}{ Confidence Interval } \\
\cline { 4 - 5 } & & & Lower bound & Upper bound \\
\hline Time worrying & 4.3 & $<0.001$ & 2.15 & 8.67 \\
\hline Strain on family & 5.81 & $<0.001$ & 2.55 & 13.19 \\
\hline Avoid outside activity & 16.6 & $<0.001$ & 6.75 & 40.85 \\
\hline Worry about others' perceptions & 1.32 & 0.4 & 0.68 & 2.55 \\
\hline Strain on job & 10.38 & $<0.001$ & 3.85 & 27.93 \\
\hline Financial burden & 3.5 & 0.001 & 1.71 & 7.61 \\
\hline
\end{tabular}


Reference group: caregivers of non-ADHD children.

Table 11. Adjusted analysis of the psychological burden items in C-ADHDC.

\begin{tabular}{|c|c|c|c|c|c|c|c|c|}
\hline & \multicolumn{4}{|c|}{ Adjusted analysis $* 1$} & \multicolumn{4}{|c|}{ Adjusted analysis $* 2$} \\
\hline & & & Confid & ce Interval & & & Confid & ce Interval \\
\hline $\begin{array}{l}\text { Dependent } \\
\text { Variables }\end{array}$ & $\begin{array}{l}\text { Odds } \\
\text { ratio }\end{array}$ & $\mathrm{P}$ value & $\begin{array}{l}\text { Lower } \\
\text { bound }\end{array}$ & $\begin{array}{l}\text { Upper } \\
\text { bound }\end{array}$ & $\begin{array}{l}\text { Odds } \\
\text { ratio }\end{array}$ & $\mathrm{P}$ value & $\begin{array}{l}\text { Lower } \\
\text { bound }\end{array}$ & $\begin{array}{l}\text { Upper } \\
\text { bound }\end{array}$ \\
\hline Time worrying & 6.9 & $<0.001$ & 2.97 & 16.44 & 15.79 & $<0.001$ & 5.24 & 65.33 \\
\hline Strain on family & 5.36 & $<0.001$ & 2.09 & 13.73 & 3.52 & 0.002 & 1.99 & 12.67 \\
\hline $\begin{array}{l}\text { Avoid } \text { outside } \\
\text { activity }\end{array}$ & 12.55 & $<0.001$ & 4.52 & 35.1 & 20.28 & $<0.001$ & 4.75 & 86.48 \\
\hline $\begin{array}{l}\text { Worry about } \\
\text { others' perceptions }\end{array}$ & 1.34 & 0.45 & 0.61 & 2.97 & 1.43 & 0.51 & 0.48 & 4.26 \\
\hline Strain on job & 17.99 & $<0.001$ & 4.80 & 37.35 & 13.06 & 0.003 & 2.36 & 42.24 \\
\hline Financial burden & 5.25 & 0.001 & 2.18 & 12.67 & 3.74 & 0.03 & 3.03 & 12.42 \\
\hline
\end{tabular}

Reference group: caregivers of non-ADHD children. $* 1$ : adjusted for sociodemographic data (child gender, parent education, marital status and having another child with a mental health problem)/*2: adjusted for sociodemographic data and conduct scores.

\section{ADHD predicts caregiver depression and anxiety}

Tables 12 and 13 depict regression analysis for stress, anxiety, and depression. After adjusting for both sociodemographic data and conduct scores, both factors served as confounders in the model, and the Odd's Ratios for each of depression and anxiety in C-ADHDC was significant ( $\mathrm{p}<0.05$ ). ORs for each of depression and anxiety were 4.7 and 3.7 respectively. Stress on the other hand was insignificant.

Table 12. Crude analysis of DASS-21 scores (dependent variables) in caregivers of an ADHD child (independent variable).

\begin{tabular}{|c|c|c|c|c|}
\hline \multirow{3}{*}{ Dependent variables: } & \multicolumn{4}{|c|}{ Crude Analysis } \\
\hline & & & \multicolumn{2}{|c|}{ Confidence Interval } \\
\hline & Odds Ratio & P value & Lower bound & Upper bound \\
\hline Depression & 3.9 & 0.001 & 1.79 & 8.49 \\
\hline Anxiety & 2.81 & 0.02 & 1.14 & 6.96 \\
\hline Stress & 2.09 & 0.05 & 0.98 & 4.45 \\
\hline
\end{tabular}

Reference group: caregivers of non-ADHD children.

Table 13. Adjusted analysis of DASS-21 scores (dependent variables) in caregivers of an ADHD child (independent variable).

\begin{tabular}{|l|l|l|l|l|l|}
\hline \multirow{2}{*}{$\begin{array}{l}\text { Dependent } \\
\text { variables }\end{array}$} & \multicolumn{3}{|l|}{ Adjusted Analysis 1* } & \multicolumn{2}{l|}{ Adjusted Analysis 2* } \\
\cline { 2 - 5 } & & $\begin{array}{l}\text { Confidence } \\
\text { Interval }\end{array}$ & $\begin{array}{l}\text { Confidence } \\
\text { Interval }\end{array}$ \\
\hline
\end{tabular}




\begin{tabular}{|l|l|l|l|l|l|l|l|l|}
\hline & $\begin{array}{l}\text { Odds } \\
\text { Ratio }\end{array}$ & P value & $\begin{array}{l}\text { Lower } \\
\text { bound }\end{array}$ & $\begin{array}{l}\text { Upper } \\
\text { bound }\end{array}$ & $\begin{array}{l}\text { Odds } \\
\text { Ratio }\end{array}$ & P value & $\begin{array}{l}\text { Lower } \\
\text { bound }\end{array}$ & $\begin{array}{l}\text { Upper } \\
\text { bound }\end{array}$ \\
\hline Depression & 3.7 & 0.01 & 1.37 & 10.05 & 4.69 & 0.01 & 1.37 & 10.05 \\
\hline Anxiety & 4.95 & 0.006 & 1.58 & 15.53 & 3.70 & 0.04 & 1.97 & 10.41 \\
\hline Stress & 1.63 & 0.3 & 0.63 & 4.21 & 2.55 & 0.10 & 0.81 & 8.07 \\
\hline
\end{tabular}

Reference group: caregivers of non-ADHD children/1 adjusted for sociodemographic data (children's age, children's sex, parents' age, parents' education, caregiver employment, economical status and having another child with a mental health problem)/ 2 adjusted for sociodemographic data and conduct.

\section{DISCUSSION}

The first aim of the study was to investigate if a child's ADHD predicts caregiver burden in aspects such as social life, occupation, and financial burden... This was affirmed by the regression analysis that showed higher Odds Ratios for almost all psychological burden variables in the case group compared to the control group. Second, the study also aimed to see if a child's ADHD influences the caregiver's mental health. As a result, CADHDC were more likely to show higher scores of depression and anxiety than C-NDC and mothers were more affected than fathers. Finally, both caregiver burden and mental health were positively correlated with the child's ADHD severity; the more severe the child's ADHD the more the psychological burden and the more likely that the caregivers will be depressed and/or anxious. This model is thus consistent with previous research indicating that both caregiver burden and depression and/or anxiety are predicted by a child's ADHD. If the model is thus correct, then the caregivers' mental health should be targeted simultaneously with the treatment of a child's ADHD.

\section{ADHD predicts caregiver burden}

The examination of psychological burden variables in nonwestern societies has been hampered by various cultural issues. It has been widely speculated that people living in nonwestern societies such as Lebanon do not express their distress as encapsulated in DSM and ICD-10 (Ohaeri et al., 2010). One hypothesis indicated that distress in such populations is often expressed in "somato-psychic" rather than "psychological" ways since psychological complaints are often less accepted than somatic ones, a communication style that has been thought to reflect the communal nature of Arabs (Lee, 2011; and Dardas, 2014). However, despite such sociological cautions, this study clearly indicates that the indices of psychological burden are widely endorsed among CADHD$\mathrm{C}$ in Lebanon. The psychological burden was present and quantified with the CAPPAadjusted survey among CADHD-C and CNDC whose demographic variables were almost similar. In that regard, after adjusting for sociodemographic data and conduct scores, all items of the psychological burden survey that were significant at the crude level remained so. However, the psychological burden of ADHD was confounded by sociodemographic data and conduct scores. This may be due to the fact that better demographic factors might predict decreased burden and conduct scores and male children are known to confound 
maternal caregiver strain (Cadman et al., 2012; Bussing et al., 2003; and King et al., 1999). In general, the highest odds ratios in the psychological burden model were for the following items: "Avoiding outside activities with the child" and "Time spent worrying"; where C-ADHDC were approximately 20 times more likely to avoid outside activities with their ADHD child and 16 times more likely to worry about their ADHD child than C-NDC. In that regard, caregivers' inflated response to avoiding outside activities with their ADHD child is not surprising, especially in a Middle Eastern society where acceptance to children with mental health problems is less conveyed (Bussing et al., 2003). Such social avoidance might stem from the fact that caregivers of children with mental disorders usually develop affiliated stigma which is portrayed by e.g., the parents of a child with ADHD feeling shame and as a result isolating themselves and avoiding social contact (Mikami et al., 2014). Since affiliated stigma would be fortified when the caregiver is seen with his child in public, it is understandable why caregivers of children with ADHD would perceive and internalize the negative societal views of ADHD and avoid social activities with the child altogether (Hansen et al., 2018). Moreover, it is important to note that Lebanon still does not does not have a national policy on mental health, hence stigmatization and lack of social acceptance joined with diminished readiness for the national integration of children with mental health problems in the Lebanese population might stimulate more worrying from the caregiver's behalf especially concerning their child's future more so than those in different populations where governments, schools and even occupational institutions are more equipped to integrate individuals with psychological disorders (Lee, 2011).

\section{ADHD predicts caregiver depression and anxiety}

Regression analysis was performed on DASS-21 indices. After examining the results, it can be concluded that depression and anxiety were influenced by sociodemographic data and the child's conduct score with C-ADHDC children being approximately 5 and 4 times more likely to be depressed and/or anxious than C-NDC respectively. We can thus note that a child's ADHD predicts caregiver depression and anxiety. Results are concordant with several other studies (Harrison and Sofronoff, 2002; West et al., 1999; and Cussen et al., 2012). In fact, paternal depression is to some extent caused by the parents' self-perception of being stigmatized by other parents (Norvilitis et al., 2002), but the bulk of this depression indeed lies in parent dissatisfaction due to the ADHD child's symptoms such as: hyperactivity, lack of concentration, or anger and disobedience (Whalen et al., 2011). Such conditions are known to aggravate the parents' ability to fully manage their child thus creating a sense of dissatisfaction in their parenting performance which ultimately leads to depressive symptoms. Note that such dissatisfaction differs from mothers to fathers. For mothers, child inattention and oppositional-conduct problems contribute uniquely to role dissatisfaction and paternal depression whereas for fathers, parenting distress is mostly associated to child oppositional or aggressive behaviors (Podolski and Nigg, 2011).

\section{Sociodemographic data}

In general, the case and control group did not vary greatly when it comes to their sociodemographic data. However, there were lower percentages of caregivers who have 
a university degree and a higher rate of illiteracy in the case group compared to the control group. Such observation implies that ADHD occurs across the board of socio-educational background as it has been shown in other populations, (Rogers et al. 2009). Furthermore, more caregivers in the case group had children with mental health problems other than ADHD (35\% vs $4.2 \%$ ). This result seems understandable as siblings of ADHD children are at increased risk for conduct and emotional disorders due to them feeling personally victimized by their sibling's aggressive behavior and conduct disorder; as previously stated, a common comorbidity to ADHD. In fact, as a result of the ADHD symptoms and consequent disruption, many siblings often describe feeling anxious, worried, and sad (Harpin, 2005) and (Kendall, 1999). Finally, male children with ADHD outnumbered female ones which was expected as genetic studies show that ADHD is linked with being male and boys are four to ten times more likely to be diagnosed with ADHD than girls. Research states that such discrepancy in diagnosis may not necessarily be due to etiological factors but rather a difference in symptom presentation which may lead to diagnosis bias (Timimi and Taylor, 2004; and Adams, 2007).

\section{Clinical implications}

To my knowledge this is the only study investigating multiple mental health domains and caregiver burden all within one sample. This is also the first study to apply modules of the CAPPA survey in Lebanon and add to the literature the probable presence of a direct relationship between an ADHD child's psychological burden on caregivers and the caregivers' mental status. In fact, the results highlighted above emphasize the need to consider paternal dynamic when treating an ADHD child thus launching a new multimodal treatment. Such treatment would involve a better understanding of the child's ADHD and its divergent chronicles affecting several aspects of the caregiver's life and would stimulate clinicians to tackle caregiver burden and mental health while treating their child's ADHD especially in highly severe ADHD children, since as concluded by the study, ADHD severity is positively associated to caregiver burden, depression and anxiety. The treatment would also stress on the apprehension of the family's social and occupational maladaptation being predictive factors for mental health anomalies. Hence, the therapeutic program would be based on tackling these predictive factors as well as adaptive caregiver-child functioning as a means of treating the caregiver's depression or anxiety. Moreover, it is important to note that individuals influence the outcome of an adverse situation not only by their behavioral reactions but also by their appraisal processes such as their personal meaning of life events, their cognitive appraisal of stressors (primary appraisal) and their perceptions of their coping resources (secondary appraisal). All of these significantly influence the way caregivers cope with their child's ADHD and, thus, determine their mental health outcomes (Roseman, 2001). Hence, the treatment model would also encourage caregivers to cope with their ADHD child by using positive reframing hence thinking about problems as challenges that will be overcome, as such coping strategy is associated to higher caregiver satisfaction (Podolski and Nigg, 2011). 


\section{Limitations}

This study adds tremendous value to the research platform involving parents of ADHD children, however, it is not without limitations. First, evidence suggests that mothers who are depressed are sometimes negatively biased in their perceptions of their child's symptoms (Gartstein et Al., 2009; Johnston and Short, 1993). Second, cultural attitudes and social factors may affect perceptions of child behavior and the degree of child behavior that is considered problematic which might have shifted the results with regard to western societies (Singh, 2008). Third, the present study used DASS-21, which is simply a symptom checklist and is inferior to gold-standard interviews (George et al., 2014). Moreover, the psychological burden of ADHD on caregivers was assessed by a European survey which is not a validated psychological measure. In addition, this study is limited by self-reporting bias and confounders which might have been eradicated had the subjects been matched to controls.

\section{CONCLUSION}

In conclusion, this study assesses the psychological burden that ADHD has on caregivers in addition to its impact on their mental health by using 3 measures: the DASS21 , the SDQ, and a survey adjusted from the CAPPA survey. Briefly, the study concludes that caregivers of ADHD children in Lebanon consider their child to be a psychological burden financially, socially and occupationally more than caregivers of non-ADHD children with psychological burden being positively associated to ADHD severity. Moreover, caregivers of ADHD children in Lebanon are more likely to be depressed and anxious than caregivers of non-ADHD children. And the psychological burden of ADHD seems to be positively associated to caregivers' mental health status. Finally, the mental health status also differs among gender where more mothers are affected than fathers and the more severe the child's ADHD the more depressed or anxious the caregiver is.

In prospect, future studies are needed for the assessment of the reliability of DASS in soliciting the presence of stress disorders and studies should consider matching when performing the sampling procedure in order to annihilate any confounding. Also, future longitudinal studies investigating the direction of the association between ADHD and caregiver depression, anxiety or stress might be beneficial in eradicating faults of temporal relationship found in a cross-sectional study and in improving outcomes in ADHD caregivers. Finally, cohort studies might want to dedicate efforts in studying the transactional cycle not only between the child's ADHD and a caregiver's mental health, as done in this study, but also between the caregiver's mental health and how it affects the child's disorder/prognosis via parenting styles.

In brief, this study despite its limitations, emphasizes the fact that ADHD might cause more collateral damage than one might think. And while it is important for caregivers to take care and support their ADHD children, it is even more important for them to take care of their own mental health and solicit the help of a professional whenever their mental state is destabilized. Hence, by ensuring a stable mindset, 
caregivers are able to show better parenting skills and hopefully positively influence the prognosis of their child's ADHD.

\section{REFERENCES}

Adams, C. 2007. Girls and ADHD: Are You Missing the Signs? Instructor, 116(6): 3135.

Al-Farsi, O. A. Al-Farsi, Y. M. Al-Sharbati, M. M., and Al-Adawi, S. 2016. Stress, anxiety, and depression among parents of children with autism spectrum disorder in Oman: a case-control study. Neuropsychiatric Disease and Treatment, 12: 1943-195.

Algorta, G. P. Dodd, A. L. Stringaris, A. and Youngstrom, E. A. 2016. Diagnostic efficiency of the SDQ for parents to identify ADHD in the UK: a ROC analysis. European Child and Adolescent Psychiatry, 25: 949-957. Retrieved from http://doi.org/10.1007/s00787-015-0815

Alyahri, A. Goodman, R. 2006. Validation of the Arabic strengths and difficulties questionnaire and the development and well-being assessment. East Mediterranean Health J. 12(Suppl 2): 138-46.

Amer, M. M. 2014. Arab American acculturation and ethnic identity across the lifespan: Sociodemographic correlates and psychological outcomes. In: Biopsychosocial Perspectives on Arab Americans (pp. 153-173). Springer, Boston, MA.

Azar, M., Badr, L. K. 2006. The adaptation of mothers of children with intellectual disability in Lebanon. Journal of Transcultural Nursing, 17(4): 375-380.

Bai, G. Houben-van Herten, M. Landgraf, J. M. Korfage, I. J. Raat, H. 2017. Childhood chronic conditions and health-related quality of life: Findings from a large population-based study. PloS one, 12(6): e0178539.

Becher, H. 1992. The concept of residual confounding in regression models and some applications. Statistics in medicine, 11(13): 1747-1758.

Bella, G. P. Garcia, M. C. and Spadari-Bratfisch, R. C. 2011. Salivary cortisol, stress, and health in primary caregivers (mothers) of children with cerebral palsy. Psychoneuroendocrinology, 36(6): 834-842.

Brown, J. D. 2011. Likert items and scales of measurement. Statistics, 15(1): 10-14.

Bussing, R., Gary, F. A., Mason, D. M., Leon, C. E., Sinha, K., and Garvan, C. W. 2003. Child temperament, ADHD, and caregiver strain: Exploring relationships in an epidemiological sample. Journal of the American Academy of Child and Adolescent Psychiatry, 42(2): 184-192.

Bussing, R. M. 2015. Childhood ADHD symptoms: association with parental social networks and mental health service use during adolescence. International journal of environmental research and public health, 12(9): 11893-11909.

Cadman, T. Eklund, H. Howley, D. Hayward, H. Clarke, H. Findon, J. Glaser, K. 2012. Caregiver burden as people with autism spectrum disorder and attentiondeficit/hyperactivity disorder transition into adolescence and adulthood in the United Kingdom. Journal of the American Academy of Child and Adolescent Psychiatry, 51(9): 879-888.

Whalen, K. Odgers, 1. Preston, L. and Henker, B. 2011. Dissecting Daily Distress in Mothers of Children with ADHD: An Electronic Diary Study. Journal of family 
psychology, journal of the Division of Family Psychology of the American Psychological Association (Division 43). 25: 402-11. 10.1037/a0023473.

Reynolds, R. C. 2013. Attention-Deficit/Hyperactivity Disorder (ADHD). In: A. P. Association, Diagnostic and Statistical Manual of Mental Disorders, Fifth Edition.

Cussen, A. Sciberras, E. Ukoumunne, O. C. and Efron, D. 2012. Relationship between symptoms of attention-deficit/hyperactivity disorder and family functioning: a community-based study. European journal of pediatrics, 171(2): 271-280.

Dardas, L. A. 2014. Quality of life among parents of children with autistic disorder: a sample from the Arab world. Research in Developmental Disabilities. 35(2): 278287.

Donenberg, G. and Baker, B. L. 1993. The impact of young children with externalizing behaviors on their families. Journal of abnormal child psychology, 21(2): 179198.

Farah, L. G. Fayyad, J. A. Eapen, V. Cassir, Y. Salamoun, M. M. Tabet, C. C and Karam, E. G. 2009. ADHD in the Arab world: A review of epidemiologic studies. Journal of Attention Disorders, 13: 211-222. doi:10.1177/1087054708325976.

Fares, J. Gebeily, S. Saad, M. Harati, H. Nabha, S. Said, N. and Fares, Y. 2017. Posttraumatic stress disorder in adult victims of cluster munitions in Lebanon: a 10year longitudinal study. British Medical Journal open, 7(8): e017214.

Flood, E. Gajria, K. Sikirica, V. Dietrich, C. N. Romero, B. Harpin, V. and Chen, K. 2016. The Caregiver Perspective on Pediatric ADHD (CAPPA) survey: Understanding sociodemographic and clinical characteristics, treatment use and impact of ADHD in Europe. Journal of affective disorders, 200: 222-234.

Fridman, M. Banaschewski, T. Sikirica, V. Quintero, J. and Chen, K. S. 2017. Access to diagnosis, treatment, and supportive services among pharmacotherapy-treated children/adolescents with ADHD in Europe: data from the Caregiver Perspective on Pediatric ADHD survey. Neuropsychiatric disease and treatment, 13: 947.

Gartstein, M. A. Bridgett, D. J. Dishion, T. J. and Kaufman, N. K. 2009. Depressed mood and maternal report of child behavior problems: Another look at the depressiondistortion hypothesis. Journal of Applied Developmental Psychology, 30(2): 149160.

George, B. Padmam, M. S. Nair, M. K. Leena, M. L. Prasanna, G. L. Russell, P. S. CDC Kerala. 1. 1. 2014. Diagnosis of autism among children between 2 and $6 \mathrm{y}-$ comparison of CARS against DSM-IV-TR. Indian J. Pediatr, 81(2): 125-128.

Goodman, R. 1997. The Strengths and Difficulties Questionnaire: a research note. Journal of child psychology and psychiatry, 38(5): 581-586.

Goodman, R. Ford, T. Corbin, T. and Meltzer, H. 2004. Using the Strengths and Difficulties Questionnaire (SDQ) multi-informant algorithm to screen lookedafter children for psychiatric disorders. European Child and Adolescent Psychiatry, 13(2): ii25-ii31.

Graziano, P. A. Mc Namara, J. P. Geffken, G. R. and Reid, A. 2011. Severity of children's ADHD symptoms and parenting stress: A multiple mediation model of selfregulation. Journal of abnormal child psychology, 39(7): 1073.

Gupte-Singh, K. Singh, R. R. \& Lawson, K. A. 2017. Economic Burden of AttentionDeficit/Hyperactivity Disorder among Pediatric Patients in the United States. Value in Health, 20(4): 602-609. 
Hansen, B. Szaflarski, M. Bebin, E. M. and Szaflarski, J. P. 2018. Affiliate stigma and caregiver burden in intractable epilepsy. Epilepsy and Behavior, 85: 1-6.

Harpin, V. A. 2005. The effect of ADHD on the life of an individual, their family, and community from preschool to adult life. Archives of disease in childhood, 90(Suppl 1): i2-i7.

Harrison, C. and Sofronoff, K. 2002. ADHD and parental psychological distress: Role of demographics, child behavioral characteristics, and parental cognitions. Journal of the American Academy of Child and Adolescent Psychiatry, 41(6): 703-711.

Henry, J. D. and Crawford, J. R. 2005. The short-form version of the Depression Anxiety Stress Scales (DASS-21): Construct validity and normative data in a large nonclinical sample. British journal of clinical psychology, 44(2): 227-239.

Singh, I. 2008. ADHD, culture and education, Early Child Development and Care, 178(4): 347-361, DOI: 10.1080/03004430701321555

Johnston, C. and Short, K. H. 1993. Depressive symptoms and perceptions of child behavior. Journal of Social and Clinical Psychology, 12(2): 164-181.

Kendall, J. 1999. Sibling accounts of attention deficit hyperactivity disorder (ADHD). Family process, 38(1): 117-136.

Khadra, C. Wehbe, N. Lachance Fiola, J. Skaff, W. and Nehmé, M. 2015. Symptoms of post-traumatic stress disorder among battered women in Lebanon: An exploratory study. Journal of interpersonal Violence, 30(2): 295-313.

King, G. King, S. Rosenbaum, P. and Goffin, R. 1999. Family-centered caregiving and well-being of parents of children with disabilities: Linking process with outcome. Journal of Pediatric Psychology, 24(1): 41-53. http://dx.doi.org/10.1093/jpepsy/24.1.41

Latha et al., 2012. Frequency of parental psychopathology in children with attention deficit hyperactivity disorder. Online J Heal Allied Sci., 11(1): 7.

Lauber, C. and Rössler, W. 2007. Stigma towards people with mental illness in developing countries in Asia. International review of psychiatry, 19(2): 157-178.

Lee, C. 2011. Addressing mental health needs in Lebanon; International Medical Corps https://odihpn.org/magazine/addressing-mental-health-needs-in-lebanon.

Lee, P. H., Burstyn, I. 2016. Identification of confounder in epidemiologic data contaminated by measurement error in covariates. BMC Medical Research Methodology, 16, 54. Retrieved from http://doi.org/10.1186/s12874-016-0159-6

Lovell, B. Moss, M. and Wetherell, M. A. 2012. With a little help from my friends: Psychological, endocrine and health corollaries of social support in parental caregivers of children with autism or ADHD. Research in developmental disabilities, 33(2): 6 .

Lovell, B. Moss, M. and Wetherell, M. A. 2015. The psychophysiological and health corollaries of child problem behaviors in caregivers of children with autism and ADHD. Journal of Intellectual Disability Research, 59(2): 150-157.

McCubbin, H. I. and Patterson, J. M. 1983. The family stress process: The double ABCX model of adjustment and adaptation. Marriage and family review, 6(1-2): 7-37.

Mikami, A. Y. Chong, G. K. Saporito, J. M. and Na, J. J. 2014. Implications of parental affiliate stigma in families of children with ADHD. Journal of clinical child and adolescent psychology: the official journal for the Society of Clinical Child and 
Adolescent Psychology, American Psychological Association, (Division 53) 44(4): 595-603. doi:10.1080/15374416.2014.888665

Mukaka, M. M. 2012. A guide to appropriate use of correlation coefficient in medical research. Malawi Medical Journal, 24(3): 69-71.

Muñoz-Silva, A., Lago-Urbano, R., Sanchez-Garcia, M., and Carmona-Márquez, J. 2017. Child/Adolescent's ADHD and Parenting Stress: The Mediating Role of Family Impact and Conduct Problems. Frontiers in psychology, 8, 2252. doi:10.3389/fpsyg.2017.02252

Norvilitis, J. M. Scime, M. and Lee, J. S. 2002. Courtesy stigma in mothers of children with attention-deficit/hyperactivity disorder: A preliminary investigation. Journal of Attention Disorders, 6(2): 61-68.

Ohaeri, J. U. Awadalla A. W. Gado O. M. 2010. Relationship between symptoms of major depressive and generalized anxiety disorders in an Arab population using diagnostic criteria-based instruments. Medical Science Monitor, 16(12): 103-115.

Pelham, W. E. Lang, A. R. Atkeson, B. Murphy, D. A. Gnagy, E. M. Greiner, A. R. and Greenslade, K. E. 1998. Effects of Deviant Child Behavior on Parental Alcohol Consumption Stress-Induced Drinking in Parents of ADHD Children. American Journal on Addictions, 7(2): 103-114.

Podolski, C. L. and Nigg, J. T. 2001. Parent stress and coping in relation to child ADHD severity and associated child disruptive behavior problems. Journal of clinical child psychology, 30(4): 503-513.

Preuss, U. Ralston, S. J. Baldursson, G. Falissard, B. Lorenzo, M. J. Pereira, R. R. ADORE Study Group. 2006. Study design, baseline patient characteristics and intervention in a cross-cultural framework: results from the ADORE study. European child and adolescent psychiatry, 15(1): i4-i14.

Ralston, S. J. Lorenzo, M. J. and ADORE Study Group. 2004. ADORE-AttentionDeficit Hyperactivity Disorder Observational Research in Europe. European child and adolescent psychiatry, 13(1): i36-i42.

Richa, S. Rohayem, J. Chammai, R. Kazour, F. Haddad, R. Hleis, S. Gerbaka, B. 2014. ADHD prevalence in Lebanese school-age population. Journal of attention disorders, 18(3).

Riley, A. W. Coghill, D. Forrest, C. B. Lorenzo, M. J. Ralston, S. J. Spiel, G. ADORE Study Group. 2006. Validity of the health-related quality of life assessment in the ADORE study: Parent Report Form of the CHIP-Child Edition. European child and adolescent psychiatry, 15(1): i63-i71.

Rogers, M. A. Wiener, J. Marton, I. and Tannock, R. 2009. Parental involvement in children's learning: Comparing parents of children with and without AttentionDeficit/Hyperactivity Disorder (ADHD). Journal of school psychology, 47(3): 167-185.

Roseman, I. J. and Smith, C. A. 2001. Appraisal theory. Appraisal processes in emotion: Theory, methods, research, 3-19.

Seltzer, M. M. Greenberg, J. S. Hong, J. Smith, L. E. Almeida, D. M. Coe, C. and Stawski, R. S. 2010. Maternal cortisol levels and behavior problems in adolescents and adults with ASD. Journal of autism and developmental disorders, 40(4): 457469. 
Shamai, M. and Kimhi, S. 2006. Exposure to threat of war and terror, political attitudes, stress, and life satisfaction among teenagers in Israel. Journal of Adolescence, 29(2): 165-176.

Taouk, M., Lovibond, P. F., Laube, R. 2001. Psychometric properties of an Arabic version of the Depression Anxiety Stress Scales (DASS21). Report for New South Wales Transcultural Mental Health Centre, Cumberland Hospital, Sydney.

Theule, J. Wiener, J. Tannock, R. Jenkins, J. M. 2013. Parenting stress in families of children with ADHD: a meta-analysis. Emotional Behavioral Disorders, 21(1): 3-17.

Timimi, S. and Taylor, E. 2004. ADHD is best understood as a cultural construct. The British Journal of Psychiatry, 184(1): 8-9.

Turgay, A. et al. 2005. Treatment of comorbidity in conduct disorder with attentiondeficit hyperactivity disorder (ADHD). Essential psychopharmacology, 6(5): 277-290.

West, J. Houghton, S. Douglas, G. Wall, M. and Whiting, K. 1999. Levels of self-reported depression among mothers of children with Attention-Deficit! Hyperactivity Disorder. Journal of Attention Disorders, 3(3): 135-140.

Wrobel, H. 2013. Parent Practices and Identity Outcomes in Arab Youth. International Symposium on Arab Youth. 4.

Wrońska, N. Garcia-Zapirain, B. and Mendez-Zorrilla, A. 2015. An iPad-Based tool for improving the skills of children with attention deficit disorder. International Journal of environmental research and public health, 12(6): 6261-6280.

Yule, G. U. 1912. On the methods of measuring the association between two variables. The first identification of the phi-coefficient. J. R. Statistics in Society, 75: 576642.

Zahr, L. K. and Hattar-Pollara, M. 1998. Nursing care of Arab children: Consideration of cultural factors. Journal of Pediatric Nursing, 13(6): 349-355.

Zhao, X. Page, T. F. Altszuler, A. R. J. 2019. Abnorm Child Psychol. 37: 981-993. https://doi.org/10.1007/s10802-019-00518-5 